\title{
Assessment of subsidence risk associated with aquifer storage and recovery in the Coastal Lowlands Aquifer System, Houston, Texas, USA
}

\author{
Van Kelley $^{1}$, Michael Turco ${ }^{2}$, Neil Deeds ${ }^{1}$, Christina Petersen $^{2}$, and Chris Canonico ${ }^{2}$ \\ ${ }^{1}$ INTERA, Inc., Austin, Texas, 78757, USA \\ ${ }^{2}$ Harris-Galveston Subsidence District, Friendswood, Texas, 77058, USA
}

Correspondence: Van Kelley (vkelley@intera.com)

Published: 22 April 2020

\begin{abstract}
In the Houston, Texas region, groundwater use is regulated by the Harris-Galveston Subsidence District (District) because of historical regional subsidence from groundwater development. The District regulates groundwater production in the Coastal Lowlands Aquifer System (CLAS) to mitigate subsidence through the implementation of District Groundwater Regulatory Plan. The District has successfully reduced groundwater pumping as a percent of demand regionally while controlling subsidence through the implementation of alternative water supplies. Aquifer Storage and Recovery (ASR) is an alternative water supply strategy that provides a means to store water underground and increase water supply more cost effectively than traditional storage expansion strategies. Groundwater users in the District are interested in the many potential benefits of ASR as a water supply strategy. Little is known about the potential effects on compaction and land surface subsidence resulting from ASR operations. Recognizing this, the District funded research on the potential subsidence risk associated with ASR. Two hypothetical, though representative, ASR projects were developed and analysed: (1) an industrial ASR project meant to provide water supply during a drought of record (DOR), and (2) a municipal ASR project designed to provide an annual municipal summer peaking water supply. Simulations of groundwater hydraulics and subsidence were performed at three potential locations within the CLAS to provide insight into variability associated with location and aquifer depth. Theoretical simulations confirmed the potential for subsidence associated with the application of ASR in the CLAS, although operating an ASR for summer peaking needs has less potential risk of subsidence than the DOR scenario in the scenarios simulated. The study simulations provide insight into how an ASR project may be designed and operated to minimize compaction and potential subsidence. Based on this study, ASR operated to address summer peaking showed the greatest potential to reduce additional compaction verses sourcing all water from groundwater. This theoretical study provides a basis for future research on subsidence associated with ASR and provides a framework for consideration for the regulation of ASR within the District.
\end{abstract}

\section{Introduction and statement of research needs}

In response to regional subsidence in the Houston Region, the Texas Legislature created the Harris-Galveston Subsidence District (District) in 1975 to provide for the regulation of groundwater withdrawal throughout Harris and Galveston counties in south-east Texas for the purpose of preventing land subsidence. The District's jurisdictional area includes the City of Houston, surrounding municipalities, and the in- dustrial and port complex of the Houston Ship Channel and Galveston Bay.

Historically, the Coastal Lowlands Aquifer System (CLAS) in the District had been the primary water source for the region's municipal, industrial, and agricultural water supply. The Chicot, Evangeline, and Jasper aquifers are the three primary water bearing units of the aquifer system, with the Chicot being the shallowest (youngest) and the Jasper being the deepest (oldest). Historical reliance on groundwater from 


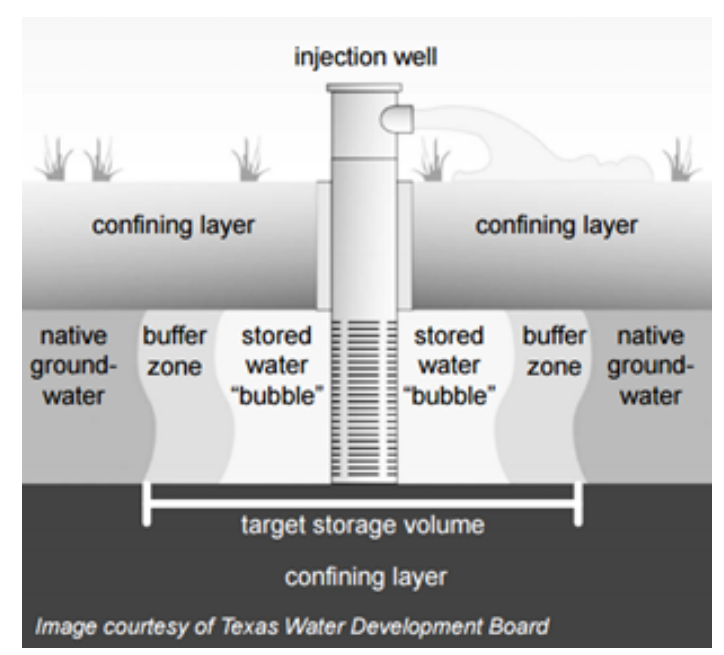

Figure 1. Schematic of an ASR well at the end of recharge and prior to recovery showing the stored water and the buffer zone (after Pyne, 2005).

the Chicot and Evangeline aquifers in the Harris-Galveston Subsidence District (District) led to significant regional subsidence occurring by the 1970s (Kasmarek et al., 2016) in response to regional lowering of aquifer water levels.

Since 1975, groundwater regulations set forth by the District has resulted in increased aquifer water-levels and slowing and/or cessation of subsidence in regulatory areas closest to the Gulf of Mexico. The potentiometric water-levels (water levels) in the CLAS in the District have rebounded greater than $60 \mathrm{~m}$ from the historical minimum water-level in response to pumping curtailment. To meet the District's regulations, water providers are required to develop alternative water supplies (primarily treated surface water). Water providers in the region have begun considering Aquifer Storage and Recovery (ASR) as a potential alternative water supply strategy that offers redundancy of supply during periods of drought or other natural disasters (i.e., floods).

ASR is a proven water supply strategy to increase the availability of either groundwater or surface water through the storage of water in an aquifer using a well or wells (Pyne, 2005). Just as surface water reservoirs are routinely used to increase surface water availability for the future, ASR uses an aquifer to increase availability of either stored surface water, groundwater or reuse water. A properly designed ASR project will define a yield (storage volume) that the ASR project will supply over some time horizon. Figure 1 is a schematic of a hypothetical ASR well showing the stored water, often referred to as "the bubble", the buffer zone which represents a volume of mixed recharge and native aquifer groundwater and the target storage volume which encompasses both the bubble and the buffer zone.

A typical ASR project includes periods of recharge when water is being stored within the aquifer and periods of recovery when water is being pumped from the aquifer. Dur- ing recharge periods the water level at and near the well will rise greater than it was prior to recharge (static water level). During recovery periods the water level will fall below static water levels just as occurs in standard well pumping. The duration of recharge and recovery periods can vary significantly depending upon the volume of water stored and the needs of the project. Because ASR includes periods of pumping during recovery of stored water, it can cause compaction and subsidence.

This study contains three key elements; a literature review of ASR in subsidence prone environments, numerical simulations of representative hypothetical ASR projects and a discussion of key considerations to support the future management and potential regulation of ASR in the District. Because of the theoretical nature of the study, recommendations were also made for future research and data needs to better constrain our understanding of ASR and associated potential subsidence.

\section{Mechanisms of subsidence and relevance to ASR}

The CLAS is composed of a complex sequence of sands and clays. Compaction and resulting subsidence in the CLAS in the study area is caused by the reduction of the pore pressure in the clay beds as a result of groundwater pumping. This decline in pressure in the aquifer leads to a decrease in pore pressure within the numerous clay lenses, which then begin to compact due to increased effective stress (Poland and Davis, 1969). This permanent compaction of the sediments, caused by groundwater withdrawal, is the largest contributor to land subsidence throughout the region.

Compaction can be a slow process and the time it takes for compaction to occur within a clay bed depends on several clay characteristics. Generally, the thickness of the clay beds, the percentage of clay deposits relative to the total thickness of the aquifer, and the depth of burial of the deposits determine the potential for compaction and risk for subsidence.

Historical subsidence in the District has regionally exceeded $2 \mathrm{~m}$ and locally exceeded $3 \mathrm{~m}$ in the District region. The District, in cooperation with other agencies and institutions in the region regularly monitors groundwater production, groundwater levels and subsidence in the region. The United States Geological Survey (USGS) monitors water levels and operates 11 extensometers in the District. The District and the University of Houston operate a land surface deformation monitoring network with over 200 stations located within the District Region.

Because ASR requires pumping in addition to recharge, there is potential for an ASR project to induce compaction and potentially contribute to subsidence in the CLAS.

Five ASR case studies (Kelley and Deeds, 2019) were reviewed for this study: San Juaquin Valley, CA; Santa Clara Valley, CA; Antelope Valley, CA; Las Vegas, NV; and Shanghai, China. The literature review showed that well- 
documented case studies for Managed Aquifer Recharge (MAR) in subsidence prone aquifers significantly outnumbered ASR case studies. There are limited publicly documented case studies of subsidence associated with ASR. ASR case studies reviewed were the Las Vegas ASR and MAR project and the Antelope Valley, California ASR cycle test performed by the USGS. In both cases, measurable subsidence occurred in the vicinity of the ASR projects during their operation or testing.

A review of the case studies also found that in aquifers which have historically undergone significant regional subsidence, such as the CLAS in the District, the rate of subsidence can increase in response to increased effective stress caused by subsequent pumping, even when pumping water levels remain above the historical minimums. This has been documented in several areas of California and has been observed in the District in response to renewed pumping during a regional drought in 2011. Therefore, maintaining water levels above historical lows during withdrawal does not guarantee that the cessation of compaction of the aquifer and subsidence. These facts complicate the prediction of potential subsidence from ASR projects in aquifers that have experienced significant regional subsidence such as the CLAS in the District.

Because the pressure reduction in lower conductivity clay interbeds is inherently transient, compaction occurs over years if not decades and the effective stress controlling further subsidence in an aquifer with a complex history of water level decline, rebound and subsidence is very uncertain. Stated differently and in context to the ASR problem, what level of additional drawdown during recovery will re-initiate higher subsidence rates? The literature has shown that in aquifers with significant subsidence, the effective stress on the aquifer does not represent the effective stress predicted by the lowest observed water levels. This raises a complicating question when considering additional pumping or ASR in the shallow portions of the CLAS that have undergone significant historical compaction and where groundwater levels have significantly rebounded.

To account for the uncertainty in the current effective stress of the system, simulations performed in this study assume that the initial static water level prior to the ASR project operation defines the preconsolidation state or effective stress on the aquifer. This assumption is regulatorily conservative by preventing overestimation of the benefit of ASR to mitigate subsidence.

\section{Hypothetical ASR cases and simulation of resulting compaction}

Two hypothetical ASR projects (cases) that vary in their recharge and recovery time periods and periodicity were considered; a drought of record (DOR) strategy and a seasonalpeaking strategy. The DOR project assumes recharge of ex-

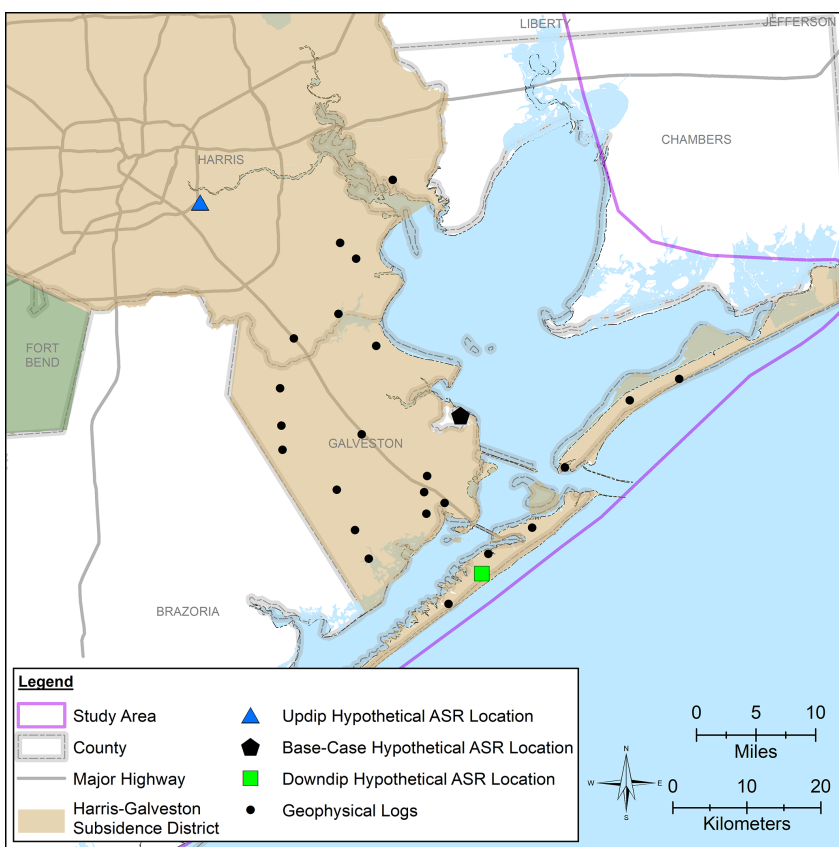

Figure 2. Location of the three hypothetical ASR project sites simulated (Kelley and Deeds, 2019).

cess contract water over a 5 year period followed with the withdrawal of the total storage volume over a period of 5 years during a period of drought when it is assumed the availability of contract water will be limited. Alternatively, the seasonal-peaking strategy (a common strategy for municipal ASR projects) assumes excess water supply in the winter is recharged in the project with the total storage volume withdrawn during the summer months when need is highest.

The initial location for the hypothetical DOR ASR project is termed the base case location and is located near the city of Texas City, TX, USA. To investigate hydrogeologic variability inherent in the CLAS, two additional project locations were considered: one on Galveston Island (downdip site) and one just southeast of Houston, TX in the far northwest edge of HGSD Regulatory Area 1 (updip site). Figure 2 shows the location of the three hypothetical ASR project areas.

A numerical groundwater flow model was developed to estimate compaction associated with the hypothetical ASR projects operating with the two water management strategies. The numerical model was developed using the United States Geological Survey (USGS) code MODFLOW-NWT (Niswonger et al., 2011) which supports the USGS subsidence (SUB) package (Höffmann et al., 2003).

The water source for the hypothetical ASR projects simulated was assumed to be treated surface water sourced from the Brazos River. An analysis of geochemical compatibility of the source water with groundwater was performed based upon measured groundwater quality data and inferred formation mineralogy. Results of the geochemical analysis suggest that there could be potential for calcite precipitation which 
could reduce the ability of the aquifer to store and transmit water. Additionally, there could be potential for other chemical reactions as result of mixing the source water with groundwater which could mobilize arsenic and other metals, increasing the total dissolved solids of the recovered water. Pre-recharge treatment of the injected water and proper design of an ASR buffer zone can mitigate any potential water quality issues identified in this study though good mineralogic data is a data gap which would require coring within the recharge intervals and the overlying and underlying confining units.

\section{Potential of subsidence induced by compaction from ASR in the Chicot and Evangeline Aquifers}

Compaction was simulated for the DOR case and the summer peaking case at each of the three hypothetical sites. In addition, a simplified hypothetical ASR model was developed simulating a single ASR well completed in one hydrogeologic unit to isolate how various aquifer characteristics and ASR operational parameters can affect compaction.

Figure 3 plots maximum predicted compaction versus time in the immediate vicinity of the ASR well for the hypothetical DOR case and the summer peaking case at the basecase location (blue lines). Figure 3 also plots maximum predicted compaction versus time for both sites from only production of an equal volume of groundwater as recovered in the ASR well (dashed lines). The difference in predicted compaction between the two curves provides one measure of the relative benefit of ASR over just groundwater pumping for an equal volume of groundwater. Model simulations predict that approximately $7.3 \mathrm{~cm}$ of maximum compaction would occur for the DOR case at the base-case location after one operational cycle (Fig. 3). At a radial distance of $3.048 \times 10^{2} \mathrm{~m}$ from the ASR well(s), predicted compaction ranged from $25 \%$ to $30 \%$ of predicted compaction in the immediate vicinity of the ASR well(s). For both the DOR and summer peaking cases, ASR results in less compaction than production with no recharge. For the hypothetical DOR case, the benefit of ASR versus only groundwater production is a $50 \%$ reduction in compaction after the first year of recovery, and approximately $3 \%$ reduction in total compaction at the end of a 5-year recovery period (Fig. 3). In the summer peaking case, the benefit of ASR versus only groundwater pumping is greater than a $30 \%$ reduction in compaction after 20 cycles of annual operation (Fig. 3 ).

The simulations performed to date are limited in scope and are for hypothetical projects. Potential subsidence associated with an actual ASR project will be dependent on the specific operational details and location of the project. As a result, future proposed ASR projects in the District will require a site-specific analysis of their potential benefits as compared to traditional groundwater pumping based upon that project's operational details and the detailed hydrogeology at the site.

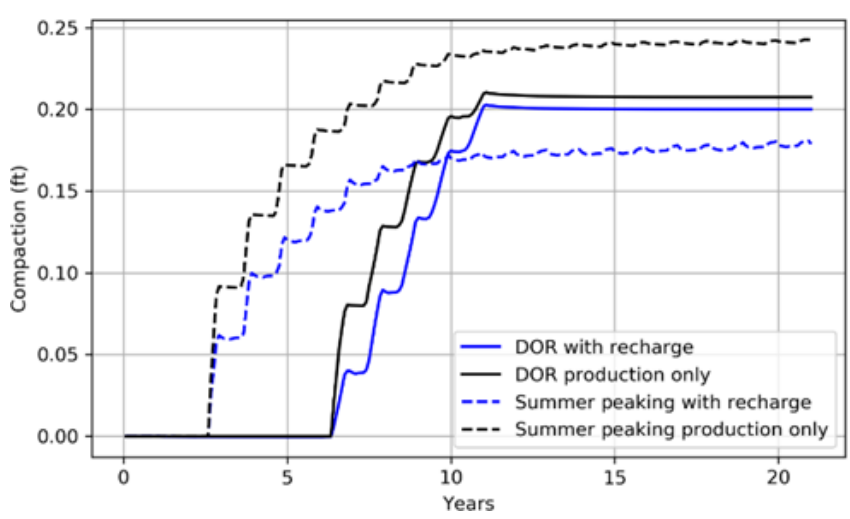

Figure 3. Compaction versus time for the DOR and summer peaking projects, comparing ASR simulations (recharge and production) to simulations with only production.

Model simulation results show that properly designed ASR projects can reduce the "effective drawdown" on the aquifer for a given groundwater yield and thus result in less compaction and potential subsidence. Results suggest that optimal cycling of recharge and withdrawal can reduce the "effective drawdown" and thereby reduce subsidence.

Designing an ASR project to minimize the potential for subsidence presents another design constraint to those traditionally considered. Model results suggest that an ASR project can be designed and operated to minimize potential compaction. Key components of an ASR project that may be modified to limit the potential compaction are: (1) maximizing the well spacing; (2) decreasing the recovery rate(s); (3) decreasing recovery duration prior to the next recharge cycle; and (4) targeting high transmissivity, low clay content intervals as the storage formation(s).

\section{Relevance and potential impact on future regulations}

This study is the first District study of the potential for subsidence from the implementation of ASR and provides new insights for how compaction may occur with the development of an ASR project in the Chicot and Evangeline aquifers. The results of this study have led to the development of recommendations for future data and research requirements for ASR projects in the District as well as recommendations for future District rule modifications and regulatory provisions.

Data availability. The underlying data, analysis, and documentation is archived at the Harris-Galveston Subsidence District and is available upon request.

Author contributions. MT, CP, and CC provided significant contribution regarding the hydrogeology of the CLAS in the Hous- 
ton region, the history of subsidence, and the recent shift of water providers to frontier resources and novel water management strategies. VK and ND provide significant contribution regarding the project scope, methodologies of analysis, interpretation of results, and conclusions.

Competing interests. The authors declare that they have no conflict of interest.

Special issue statement. This article is part of the special issue "TISOLS: the Tenth International Symposium On Land Subsidence - living with subsidence". It is a result of the Tenth International Symposium on Land Subsidence, Delft, the Netherlands, 17-21 May 2021.

Acknowledgements. The authors would like to acknowledge the following contributors to this study: Fred Blumberg and Ashley Evans of ARCADIS; David Pyne and Richard Glanzman of ASR Systems; Zhuping Sheng of Texas A\&M El Paso; Scott Marr of HDR, Inc. and Bill Mullican.

\section{References}

Höffmann, J., Leake, S. A., Galloway, D. L., and Wilson, A. M.: MODFLOW-2000 Ground-Water Model-User Guide to the Subsidence and Aquifer-System Compaction (SUB) Package, US Geological Survey Open-File Report 03-233, 44 pp., USGS, 2003.
Kasmarek, M. C., Ramage, J. K., and Johnson, M. R.: Water-Level Altitudes and Water-Level Changes in the Chicot, Evangeline and Jasper Aquifers and Compaction 1973-2015 in the Chicot and Evangeline Aquifers, Houston-Galveston Region, Texas, US Geological Survey Scientific Investigations Map 3365, 2016.

Kelley, V. and Deeds, N.: Assessment of Subsidence and Regulatory Considerations for Aquifer Storage and Recovery in the Evangeline and Chicot Aquifers, Report prepared for the HarrisGalveston Subsidence District, 188 pp., 2019.

Niswonger, R. G., Panday, S., and Ibaraki, M.: MODFLOW-NWT, A Newton formulation for MODFLOW-2005, US Geological Survey Techniques and Methods 6-A37, 44 pp., USGS, 2011.

Poland, J. F. and Davis, G. H.: Land subsidence due to withdrawal of fluids, in: Reviews in engineering geology, edited by: Varnes, D. J., Vol. 2, Geological Society of America, Boulder Colorado, 187-268, 1969.

Pyne, R. D. G.: Aquifer Storage Recovery - A Guide to Groundwater Recharge Through Wells, 2nd Edn., ASR Press, 608 pp., 2005 . 